\title{
Sequence of Pilin from Bacteroides nodosus 351 (Serogroup H) and Implications for Serogroup Classification
}

\author{
By PETER A. HOYNE, ${ }^{*}$ THOMAS C. ELLEMAN,$^{1}$ NEIL M. MCKERN ${ }^{1}$ \\ AND DAVID J. STEWART ${ }^{2}$ \\ Divisions of Biotechnology ${ }^{1}$ and Animal Health ${ }^{2}$, Commonwealth Scientific and Industrial \\ Research Organization, Parkville 3052, Australia
}

(Received 18 October 1988; revised 4 January 1989; accepted 19 January 1989)

The nucleotide sequence of the pilin gene from Bacteroides nodosus strain 351, currently classified as serogroup $\mathrm{H}$, subgroup $2(\mathrm{H} 2)$ has been determined. The gene encodes a single polypeptide (prepilin) of 160 amino acids and $M_{\mathrm{r}} 17150$. However, pilin isolated from $B$. nodosus 351 migrates as two distinct bands in sodium dodecyl sulphate-polyacrylamide gel electrophoresis, due to an internal peptide bond cleavage. Amino acid sequence studies of pilin from $B$. nodosus 351 have established that the cleavage occurs between ${ }_{72} \mathrm{Ala}$ and ${ }_{73} \mathrm{Ser}$ of the mature protein sequence. Comparisons of gene and amino acid sequences of pilin from $B$. nodosus 351 with the corresponding sequences from strains of serogroups $\mathrm{D}$ and $\mathrm{H} 1$ indicate that these sequences share a close relationship. However, the level of sequence identity between $B$. nodosus 351 pilin and pilin from strain 265 of serogroup $\mathrm{Hl}$ is lower than anticipated for strains within a serogroup and suggests that $B$. nodosus 265 and $B$. nodosus 351 should not be classified within the same serogroup.

\section{INTRODUCTION}

The Gram-negative rod Bacteroides nodosus is the principal causative agent of ovine footrot (Beveridge, 1941), a disease of considerable economic importance in the sheep grazing industry. Strains of $B$. nodosus can be classified into a number of serogroups based on pilus-mediated cellular agglutination. Several seroptyping schemes exist. However, the one most frequently used in Australia (Claxton et al., 1983; Claxton, 1986) classifies strains into nine serogroups designated A to I. Serogroups can be further divided, based on cross-tube agglutination studies (Claxton et al., 1983), into a current total of 18 subgroups. An alternative classification system (Day et al., 1986) divides $B$. nodosus isolates from British sheep into 17 serotypes, based on the incomplete removal of agglutinating activity from antisera after absorption by antigens of heterologous serotypes. Vaccination with either killed bacteria or purified pili, in a suitable adjuvant, will protect sheep against footrot when challenged with the same strain of $B$. nodosus (Egerton \& Burrell, 1970; Egerton \& Roberts, 1971 ; Stewart, 1978 a, b; Every \& Skerman, 1982; Stewart et al., 1983). Since protection against infection is limited to within a serogroup, multivalent vaccines are required for the control of footrot in the field.

The polar pili of $B$. nodosus are comprised of a subunit polypeptide, pilin $\left(M_{\mathrm{r}} \sim 17000\right)$, the size of which is strain dependent. Amino acid or gene sequences of pilin from $B$. nodosus strains representative of serogroups A to $\mathrm{H}$ have been published (McKern et al., 1983, 1985, 1988; Elleman \& Hoyne, 1984; Elleman et al., 1986c; Elleman \& von Ahlefeldt, 1987; Dalrymple \& Mattick, 1987; Finney et al., 1988). On the basis of sequence similarity, $B$. nodosus pilins can be divided into two easily distinguishable sets (Finney et al., 1988). The A-set includes pilins from serogroups $A, B, C, E, F$ and $G$, and the D-set includes pilins from serogroups D and $H$. Pilins from serogroup I, based on known serological reactivities (Claxton, 1986), are most probably members of the A-set. Although pilins within a set exhibit a high degree of amino acid sequence 
identity $(>60 \%)$, the degree of identity between pilins from different sets $(<40 \%)$ is no better than that between pilins from $B$. nodosus and those from other bacterial genera including Neisseria, Moraxella and Pseudomonas (Elleman, 1988). Pilins from these genera and those of $B$. nodosus are collectively known as the $N$-methylphenylalanine (mePhe) group as they all possess the unusual amino acid at the amino-terminus.

Within the $\mathrm{H}$ serogroup of $B$. nodosus, two subgroups have been distinguished on the basis of low level cross agglutination (Claxton et al., 1983). Pilins from representatives of both subgroups show two subunits in sodium dodecyl sulphate-polyacrylamide gel electrophoresis (SDS-PAGE) (Anderson et al., 1987). In order to define further the $\mathrm{H}$ serogroup and the $\mathrm{D}$-set pilins, the gene sequence of pilin from $B$. nodosus 351 (Bn351) of serogroup $\mathrm{H}$, subgroup 2 (H2) has been determined.

\section{METHODS}

Preparation of B. nodosus DNA and pili. B. nodosus 351 (Bn351) (CSIRO Animal Health Collection), originally designated B. nodosus VCS1057 (Department of Veterinary Clinical Studies, University of Sydney) and classified as serogroup $\mathrm{H}$, subgroup 2 (Claxton et al., 1983), was grown anaerobically in modified Eugon broth at $37^{\circ} \mathrm{C}$ for $48 \mathrm{~h}$. DNA and pili were prepared from the bacterial culture by methods previously described (Elleman $e t$ al., 1984; Stewart et al., 1983). Purification of pili was monitored by SDS-PAGE (Laemmli, 1970) using $15 \%(\mathrm{w} / \mathrm{v})$ acrylamide in a Bio-Rad Mini-Protean II system. In some cases 2-mercaptoethanol was omitted from the sample incubation buffer.

DNA hybridization procedures. The probe used to identify the pilin gene of Bn351 was derived from a $620 \mathrm{bp}$ DraI/BglI fragment containing the coding region of the pilin gene from B. nodosus 265 (Bn265) DNA cloned in M13mp7. Radiolabelled DNA corresponding to the Bn265 pilin gene, prepared using $\left[\alpha^{-32} \mathrm{P}\right] \mathrm{dATP}$ (Elleman $e t$ al., 1986c), was used both to screen Escherichia coli clones (Maniatis et al., 1982) for the presence of the B. nodosus 351 pilin gene and also to identify the pilin gene in endonuclease digested DNA from Bn351 or from recombinant plasmids after electrophoretic separation of DNA fragments in submerged agarose (1\%) gels and transfer to nitrocellulose membranes (Smith \& Summers, 1980). Nitrocellulose membranes were prehybridized in $50 \%$ formamide, $1 \times$ Denhardt's solution ( $0.02 \%$ Ficoll, $0.02 \%$ polyvinylpyrrolidone, $0.02 \%$ bovine serum albumin), $5 \times \mathrm{SSC}$ (SSC: $150 \mathrm{~mm}-\mathrm{NaCl}, 15 \mathrm{~mm}$-sodium citrate, $\mathrm{pH} 7.0$ ), $20 \mathrm{~mm}$-potassium phosphate, $\mathrm{pH} 7 \cdot 0$, and $0.1 \%$ sodium dodecyl sulphate at $43{ }^{\circ} \mathrm{C}$ for $5 \mathrm{~h}$ and then hybridized with the radiolabelled probe under the same conditions for $16 \mathrm{~h}$. Membranes were washed in $2 \times$ SSC at room temperature for $1 \mathrm{~h}$ prior to autoradiography.

Cloning the pilin gene. B. nodosus DNA $(10 \mu \mathrm{g})$ was digested with HindIII restriction endonuclease and fractionated by electrophoresis in a submerged agarose ( $1 \%$ gel. DNA fragments of 2.0 to $3.5 \mathrm{kbp}$ were isolated using NA45 membrane (Schleicher \& Schuell) and ligated with HindIII cut and dephosphorylated pBR322. This material was used to transform competent $E$. coli RRI. E. coli transformants harbouring the pilin gene were identified by hybridization to ${ }^{32}$ P-labelled DNA probe. Plasmid DNA (pPAH107) was extracted from one of the positive clones and purified by $\mathrm{CsCl} /$ ethidium bromide density gradient centrifugation (Radloff et al., 1967).

Nucleotide sequence determination. Nucleotide sequence was determined by the dideoxy chain-termination method (Sanger et al., 1977). The $3.1 \mathrm{kbp} \mathrm{HindIII} \mathrm{fragment} \mathrm{and} \mathrm{the} \mathrm{derivative} 1.2 \mathrm{kbp}$ and $1.7 \mathrm{kbp}$ HindIII-NheI fragments from pPAH107 were inserted into phage M13 DNA (Messing, 1983) for the preparation of templates. The sequence was determined on both strands and traversed the single NheI restriction site located within the pilin gene. Oligonucleotides were synthesized either manually (Elleman \& Hoyne, 1984) or automatically on an Applied Biosystems 381A DNA synthesizer and were purified by high performance liquid chromatography.

Separation of polypeptide chains of pilin. To determine the cleavage point within the pilin molecule, the polypeptide sub-chains were separated on the basis of their differential solubility under acidic conditions using the following procedure. A solution of Bn351 pili $\left(\sim 1 \mathrm{mg} \mathrm{m}^{-1}\right)$ in $0.05 \mathrm{M}$-sodium phosphate $/ 0.15 \mathrm{M}-\mathrm{NaCl}, \mathrm{pH} 7 \cdot 5$, was adjusted to $1 \%$ with respect to trifluoroacetic acid and kept at $4{ }^{\circ} \mathrm{C}$ overnight. The solution was centrifuged $(10000 \mathrm{~g})$ at $4{ }^{\circ} \mathrm{C}$ for $2 \mathrm{~min}$. The pellet, after washing with $1 \%$ trifluoroacetic acid, and the supernatant were further analysed.

Analysis of peptides. Amino acid analysis was performed as previously described (McKern et al., 1983). The pellet and the supernatant were digested with L-1-p-tosylamino-2-phenylethyl chloromethyl ketone-treated trypsin (Worthington) as described elsewhere (McKern et al., 1988) and the digestion products were separated by reverse phase liquid chromatography using a HiPore TP-318 column. Peptide fragments, purified by this method, were initially characterized by amino acid analysis and those of interest were further characterized by gas phase sequencing (McKern et al., 1988). 


\section{RESULTS}

\section{Identification and isolation of the pilin gene}

Bn351 DNA was digested with the restriction endonucleases HindIII, EcoRI, SphI, PstI or BamHI and fragments were electrophoretically separated in a submerged agarose $(1 \%)$ gel. After transfer of the enzymic digests to nitrocellulose and hybridization with radiolabelled DNA corresponding to the pilin gene of Bn265, autoradiography of the nitrocellulose membrane revealed single positive bands of $3 \cdot 1,13,11,13$ and $16 \mathrm{kbp}$ for the respective digests. Fragments of 2.0 to $3.5 \mathrm{kbp}$ from a HindIII digest of Bn35I DNA were subsequently ligated to pBR322 and the mixture used to transform $E$. coli RR 1 . An $E$. coli transformant containing a $3 \cdot 1 \mathrm{kbp}$ insert in pBR322 was detected using a radiolabelled pilin gene probe.

On completion of DNA sequence studies, radiolabelled DNA probes corresponding to the identified coding sequence of pilin from Bn 351 were prepared. Hybridization studies using these probes on Bn351 DNA digested with HindIII, PstI, EcoRI, and BamHI and fractionated by agarose gel electrophoresis identified only a single band in each digest, thus indicating the presence of a single copy of the pilin gene within the genome of $\mathrm{Bn} 351$. This finding is consistent with the identification of a single-copy pilin gene in other $B$. nodosus strains (Elleman et al., $1986 a, b$; Finney et al., 1988).

\section{Nucleotide sequence of pilin gene}

The nucleotide sequence derived from Bn351 (Fig. 1) contains an open reading frame encoding a single chain polypeptide of 160 amino acids and $M_{\mathrm{r}} 17150$ from the most likely initiation codon of the pilin gene, based on the rules of Stormo et al. (1982). A putative promoter has been proposed for the pilin gene of Bn198 (Johnson et al., 1986) based on sequence similarity with promoters from genes which require the ntrA gene product for transcription (Ausubel, 1984). A sequence ${ }_{288}$ TTGGCATC. . . . ACGCA, almost identical to the putative promoter of $\mathrm{Bn} 198$ pilin, is present in the pilin gene of $\mathrm{Bn} 351$. A potential transcription termination signal for RNA polymerase in the form of a region of hyphenated dyad symmetry and multiple thymidine residues (Platt, 1986) is present downstream of the coding region (Fig. 1). The potential stem and loop of the terminator is identical for $\mathrm{Bn} 351, \mathrm{Bn} 340$ and $\mathrm{Bn} 265$ and possesses a free energy $\left(\Delta G_{25}{ }^{\circ} \mathrm{C}\right)$ of $-64 \mathrm{~kJ} \mathrm{~mol}^{-1}$. The nucleotide sequence of the pilin gene shares many common features with the pilin genes of other $B$. nodosus strains and bears greatest overall similarity to $\mathrm{Bn} 340$ of serogroup D and Bn265 of serogroup H1. Comparison of nucleotide sequence of the pilin gene from $\mathrm{Bn} 351$ with the pilin genes of $\mathrm{Bn} 340$ and $\mathrm{Bn} 265$ shows $77 \%$ and $84 \%$ sequence identity respectively within the coding regions. Comparison of sequence from Bn351 with comparable sequences from $\mathrm{Bn} 340$ and $\mathrm{Bn} 265$ shows that upstream of the pilin coding region Bn351 exhibits $99 \%$ and $96 \%$ sequence identity respectively while downstream the levels of identity are $99 \%$ and $86 \%$ respectively (Fig. 2).

Codon usage within the pilin gene of $\mathrm{Bn} 351$ corresponds closely with that observed for pilin genes in other strains of B. nodosus (Elleman \& Hoyne, 1984; Elleman et al., 1986 b; Finney et al., 1988). There is a higher occurrence of $T$ relative to $C$ as the third base in the quartet codons and a higher occurrence of $A$ relative to $G$ in the third base position of both duet and quartet codons.

\section{Predicted amino acid sequence of pilin}

Comparisons of the predicted amino acid sequence of pilin (Fig. 3) from Bn351 with pilin sequences from $\mathrm{Bn} 340$ and $\mathrm{Bn} 265$ show that they are identical for the first 57 residues and relatively well conserved up to residue 77 . The remainder of the sequences have regions of high variability interspersed with relatively small regions which are identical in all three sequences. The predicted amino acid sequence of pilin from Bn351, in common with all B. nodosus prepilins, includes an amino terminal leader sequence of seven amino acid residues (Met.Lys.Ser.Leu. Gln.Lys. Gly) which is absent from the mature polypeptide. The predicted mature pilins from strains $\mathrm{Bn} 351$ and $\mathrm{Bn} 265$ from the $\mathrm{H}$ serogroup have a greater degree of sequence identity $(80 \%)$ than either of them has with the mature pilin of Bn340 of the D serogroup $(69 \%$ and $68 \%$ respectively). 

TTGCGCCGTCGCCAAACAATCCGCGCACGGTAAAAAGCCGCGgATITCCGTTTGTCCTTCTGCTAACGCTGCTAATAATAAGGCGCGATGCGACATTGAT BN265 TTGCGCCGTCGCCAAACAATCCGCGCACGGTAAAAAGCCGCGGATITCCGTTTGTCCTTCCGCTAACGCTGCTAATAATAAGGCGCGATGCGACATTGAT

BN340

BN351

BN265

BN340

BN351

BN265

BN340

BN351

BN265

BN340

BN351

BN265

BN340

8N351

BN265

BN340

BN351

BN265

BN340

BN351

8N265

BN340

BN351

BN265

BN340

BN351

BN265

BN340

BN351

BN265

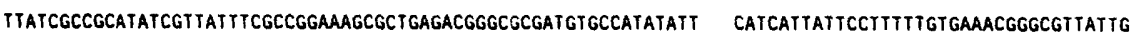

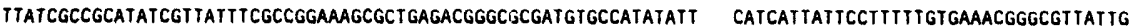

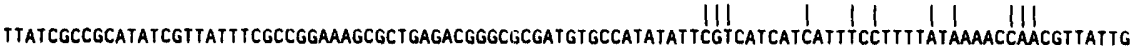

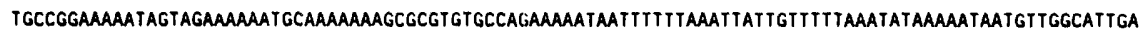

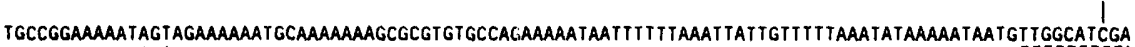
I.

TGCCGGAAAAATGGGAGAAAAAATGCAAAAAAAGCGCGTGTGCCAGAAAAATAATTTITTAACTTATTGTITTTAAATATAAAAATAATGT TGGCATTGA

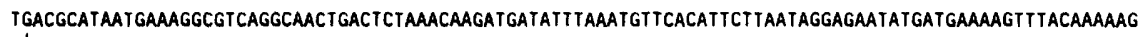

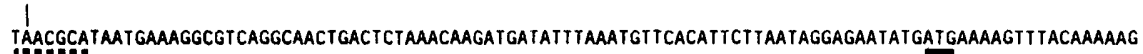

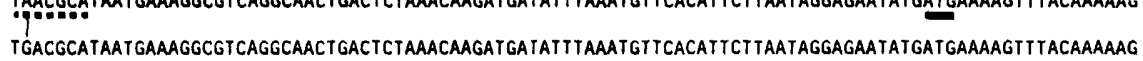

GITTIACCTTAATCGAACTCATGATTGTAGTTGCAATTATCGGTATLTTAGCTGCAATCGCTATTCCACAATACCAAAACTACATCGCTCGITCACAAGT

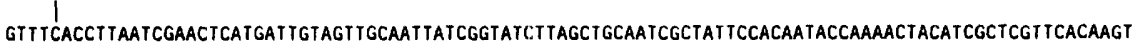

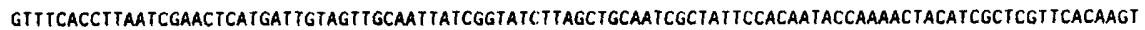

TAGCCGCGITATGTCAGAAACTGGACAAA TGCGCACCGCCATCGAAACTYGCGITTTGGATGGTAAAGAAGCCGATAAATGCTTCATTGGT TGGACTGGT

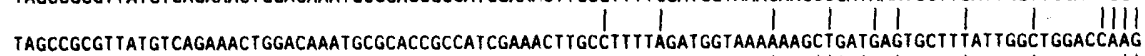

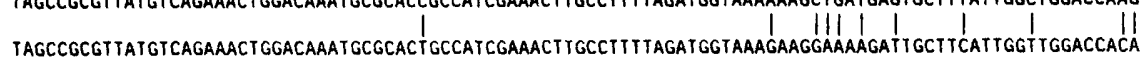

AGTAATITGTGGACGgTGAATITACTGCTGGTACC GAATCIACAGCAGCAGCAACAGGrCAAACAGgAATCACAATTAAGTACCCGGTTGCAG

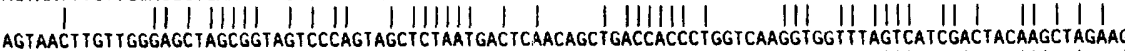
TGTTGGAGCTAGCGGTAGTCCCAGTAGCTCTAATGACTCAACAGCTGACCACCCTGGTCAGGTGGTTAGTCATCGACTACAAGCTAGAaG agtaACTTATTAGCTGCAGCTGGTGGTAGCACTA CTAACAACGCAACAGCTGCAGATCCTGGTCAAGGAGGTTGGATATTACCTACGCACTTGAAT

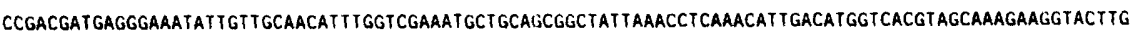
$1|1| 111111111111 \mid$

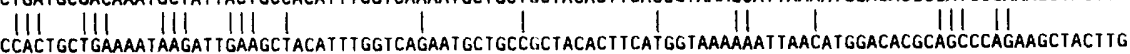

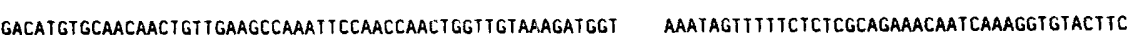

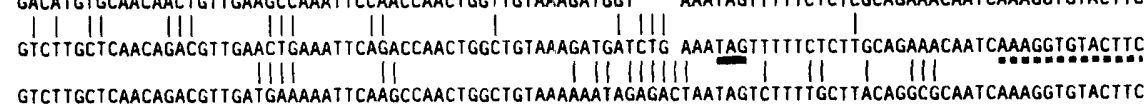

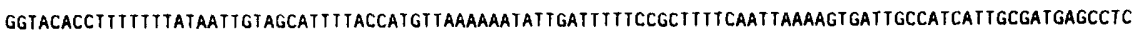

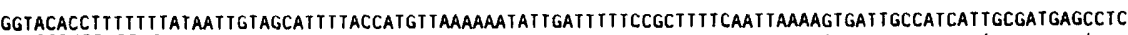

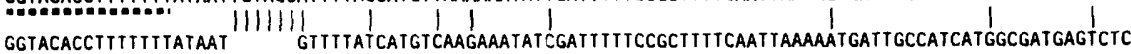

gatCATICCGCTHGCHITICTTICTGATGGTAGCTGGCGC

GATCATTCCGCTTIGCTITTICTTTCTGATGGTAGCTGGCGC GatCatTIG I I

Fig. 1. Comparison of the nucleotide sequence of the pilin gene and flanking regions of $\mathrm{Bn} 35 \mathrm{I}(\mathrm{H} 2)$ with the equivalent regions of $\mathrm{Bn} 265(\mathrm{H1})$ and $\mathrm{Bn} 340$ (D)). Sequences were aligned using the NeedlemanWunsch algorithm (Needleman \& Wunsch, 1970) with a unitary matrix and a gap penalty of 2 . Vertical lines indicate non-identical bases in adjacent sequences. Putative transcription initiation and termination signals are indicated by broken lines. Translation initiation and termination codons are indicated by solid lines. 


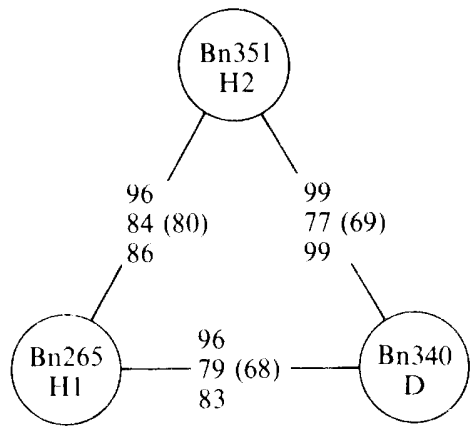

Fig. 2. Strain relationships based on percentage sequence identity between $\mathrm{Bn} 351$, Bn 340 and Bn 265 in upstream (top), coding (centre) and downstream (bottom) regions of the pilin genes presented in Fig. 1 (residues $23-378,379-858$ and $859 \cdot 1038$ respectively). Percentage amino acid sequence identities between pilins from these strains are shown in parentheses.

BN351

BN265 Met Lys Ser Leu Gln Lys Gly Phe Thr Leu Ile Glu Leu Met Ile Val Val Ala Ile Ile Gly Ile Leu Ala Ala Met Lys Ser Leu Gln Lys Gly Phe Thr Leu Ile Glu Leu Met Ile Val Val Ala Ile Ile Gly Ile Leu Ala Ala Met Lys Ser Leu Gln Lys Gly Phe Thr Leu Ile Glu Leu Met Ile Val Val Ala Ile Ile Gly Ile Leu Ala Ala Ile Ala lle Pro Gln Tyr Gln Asn Tyr lle Ala Arg Ser Gln Val Ser Arg Val Met Ser Glu Thr Gly Gln Met Ile Ala lle Pro gln Tyr GIn Asn Tyr Ile Ala Arg Ser gln Val Ser Arg Val Met Ser Glu Thr Gly Gln Met Ile Ala Ile Pro Gln Tyr Gln Asn Tyr Ile Ala Arg Ser Gln Val Ser Arg Val Met Ser Glu Thr Gly Gln Met

Arg Thr Ala lle Glu Thr Cys Val Leu Asp Gly Lys Glu Ala Asp Lys Cys Phe Ile Gly Trp Thr Gly Ser Asn arg Thr Ala Ile Glu Thr Cys Leu Leu Asp Gly Lys lys Ala Asp Glu Cys phe lle Gly trp Thr Lys Ser Asn Arg Thr Ala Ile Glu Thr Cys Leu Leu Asp Gly Lys Glu Gly Lys Asp Cys Phe Ile Gly Trp Thr Thr Ser Asn

Leu Leu Asp Gly Glu Phe Thr Ala Gly Thr Glu Ser Thr Ala Ala Ala Thr Gly Gln Thr Gly Ile Thr

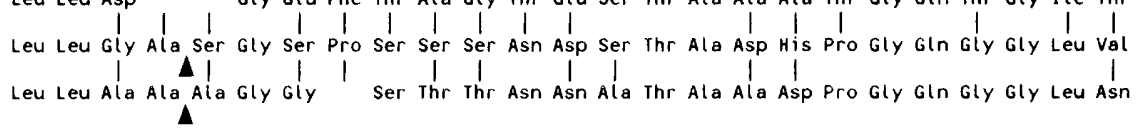

Ile Lys Tyr Pro val Ala Ala Asp Asp Glu Gly Asn Ile Val Ala Thr Phe Gly Arg Asn Ala Ala Ala Ala Ile

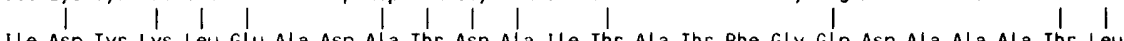
The Asp Tyr Lys Leu Glu Ala Asp Ala Thr Asn Ala Ile Thr ala Thr Phe Gly oln Asn Ala Ala Ala Thr Leu Ile Thr Tyr Ala Leu Glu Ser Thr Ala Glu Asn Lys Ile Glu Ala Thr Phe Gly Gln Asn Ala Ala Ala Thr Leu

Lys Pro Gin Thr Leu Thr Trp Ser Arg Ser Lys Glu Gly Thr Trp Thr Cys Ala Thr Thr Val Glu Ala Lys Phe

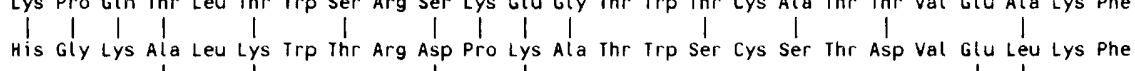
His Gly Lys Lys Leu Thr Irp Thr arg Ser Pro Ilu Ala Thr Irp Ser Cys Ser Thr Asp Val Asp Glu Lys Phe

Fig. 3. Comparison of the predicted amino acid sequence of pilin from B. nodosus $351(\mathrm{H} 2)$ with pilins from strains 265 (HI) and 340 (D). Sequences were aligned using the Needleman-Wunsch algorithm (Needleman \& Wunsch, 1970) with a unitary matrix and a gap penalty of 2 . Amino acids which differ in adjacent sequences are marked by a vertical line. Sequence numbering is relative to the first amino acid of $\mathrm{Bn} 351$ mature pilin. Arrowheads indicate the cleavage sites in pilins from Bn351 and $\mathrm{Bn} 265$. 


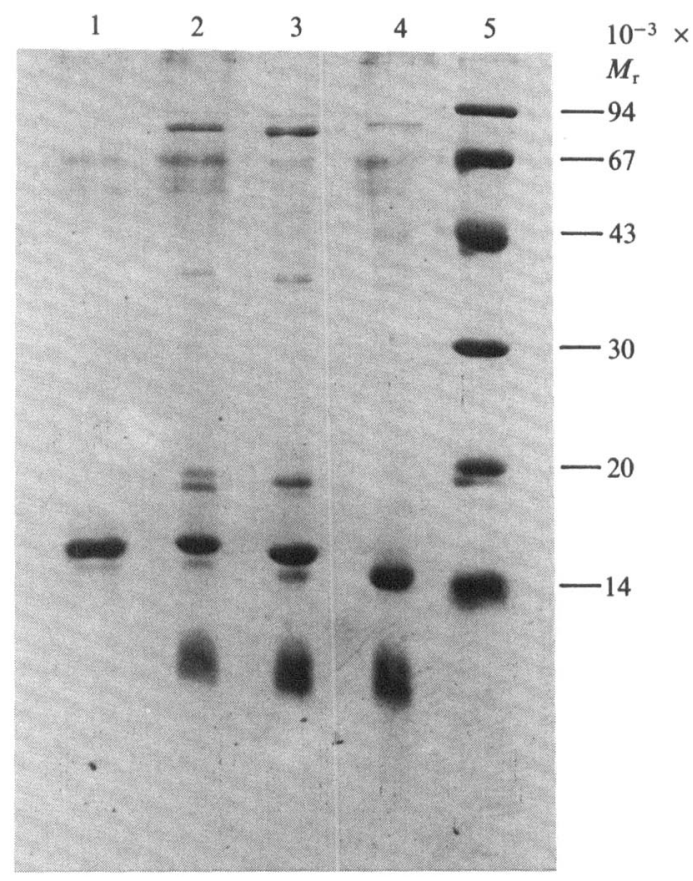

Fig. 4. SDS-PAGE (15\% acrylamide) of pilin polypeptides from B. nodosus strains 351 and 265 , stained with Coomassie brilliant blue R250. Incubation buffer contained 2-mercaptoethanol (Laemmli, 1970) unless otherwise stated. Lanes: 1, trifluoroacetic-acid-supernatant fraction of pilin from Bn351; 2, pili from $\mathrm{Bn} 351$; 3, pili from $\mathrm{Bn351}$, without 2-mercaptoethanol; 4, pili from $\mathrm{Bn} 265 ; 5, M_{\mathrm{r}}$ markers.

\section{Separation of polypeptide chains}

SDS-PAGE of strain 351 pili indicates that the pilin subunit is composed of two polypeptide chains (Fig. 4). The pilus preparation also contains contaminating membrane proteins $\left(M_{\mathrm{r}}\right.$ $30000-80000$ ) which have not been removed by repeated precipitation of pili with $0 \cdot 1 \mathrm{M}-\mathrm{MgCl}_{2}$. The supernatant material obtained following overnight treatment with $1 \%$ trifluoroacetic acid was found to consist almost exclusively of the slower-migrating subunit band of Bn351 pilin (Fig. 4). Further characterization of this material by amino acid analysis (peptide 1, Table 1) showed that it corresponded to the carboxy-terminal portion of the protein encoded by the DNA sequence, beginning near residue 73 of the mature pilin sequence. The occurrence of glycine, alanine and serine residues around this position (residues 71-75) precluded the precise determination of the cleavage position by amino acid analysis, since these amino acids are the most abundant 'background' residues encountered in amino acid analysis.

The predicted amino acid sequence of Bn351 pilin indicates that there are four cysteine residues in the molecule. Since the two polypeptide chains can be separated by differential solubility in $1 \%$ trifluoroacetic acid or by electrophoresis under non-reducing conditions (Fig. 4), covalent links must be absent between these polypeptide chains. The half-cystine residues of pilin from Bn265 are linked to form two intra-chain disulphide bonds (Elleman, 1988) and by analogy, the half-cystine residues of pilin from Bn351 are presumably similarly linked.

\section{Amino acid sequence studies}

A single amino acid sequence, mePhe. Thr. Leu. Ile. Glu. ..., corresponding to the aminoterminus found universally for $B$. nodosus pilins, was identified by amino-terminal sequence analysis of intact Bn351 pilus. Amino-terminal sequence analysis of the supernatant obtained following treatment of $\mathrm{Bn} 351$ pili with $1 \%$ trifluoroacetic acid failed to give an amino acid sequence. These data indicate that the amino terminus of the second polypeptide chain is blocked, rendering it inaccessible to amino-terminal sequencing. 
Table 1. Amino acid composition of pilin peptides from strain 351 of $B$. nodosus

Peptide 1 is the carboxy-terminal polypeptide of pilin from Bn351; peptide 2 is the peptide isolated from tryptic digestion products of the amino-terminal polypeptide of pilin from $\mathrm{Bn} 351$; peptide 3 is the peptide isolated from the tryptic digestion products of the carboxy-terminal polypeptide of pilin from Bn351.

Number of residues per peptide molecule

\begin{tabular}{|c|c|c|c|c|c|c|}
\hline \multirow[b]{2}{*}{ Amino acid } & \multicolumn{2}{|c|}{ Peptide 1} & \multicolumn{2}{|c|}{ Peptide 2} & \multicolumn{2}{|c|}{ Peptide 3} \\
\hline & Found* & $\begin{array}{c}\text { Predicted } \dagger \\
(73-153)\end{array}$ & Found* & $\begin{array}{c}\text { Predicted } \dagger \\
\quad(67-72)\end{array}$ & Found* & $\begin{array}{l}\text { Predicted } \dagger \\
\quad(73-97)\end{array}$ \\
\hline Half-Cys & - & 2 & 0 & 0 & 0 & 0 \\
\hline Asx & $10 \cdot 5$ & 11 & $1 \cdot 2$ & 1 & $4 \cdot 0$ & 4 \\
\hline Thr & $9 \cdot 0 \ddagger$ & 9 & 0 & 0 & $1 \cdot 0 \ddagger$ & 1 \\
\hline Ser & $7 \cdot 7 \ddagger$ & 8 & $1 \cdot 1 \ddagger$ & 1 & $5 \cdot 7 \ddagger$ & 6 \\
\hline Glx & $4 \cdot 6^{\top}$ & 4 & 0 & 0 & $1 \cdot 1$ & 1 \\
\hline Pro & $4 \cdot 3$ & 4 & 0 & 0 & $2 \cdot 0$ & 2 \\
\hline Gly & $7 \cdot 2$ & 7 & 0.8 & 1 & $4 \cdot 4$ & 4 \\
\hline Ala & $9 \cdot 8$ & 10 & 0.9 & 1 & 1.0 & 1 \\
\hline Val & $1 \cdot 8$ & 2 & 0 & 0 & 0.8 & 1 \\
\hline Met & $0 \cdot 1$ & 0 & $0 \cdot 1$ & 0 & 0 & 0 \\
\hline Ile & $1 \cdot 7$ & 2 & 0 & 0 & 0.7 & 1 \\
\hline Leu & $6 \cdot 1$ & 6 & $2 \cdot 2$ & 2 & 1.0 & 1 \\
\hline Tyr & $1 \cdot 0$ & 1 & 0 & 0 & 1.0 & 1 \\
\hline Phe & $2 \cdot 0$ & 2 & 0 & 0 & 0 & 0 \\
\hline Lys & 6.9 & 7 & 0 & 0 & $1 \cdot 1$ & 1 \\
\hline His & 1.9 & 2 & 0 & 0 & 1.0 & 1 \\
\hline Trp & - & 2 & - & 0 & - & 0 \\
\hline Arg & $2 \cdot 0$ & 2 & 0 & 0 & 0 & 0 \\
\hline & $\begin{array}{l}-, \text { Not } \\
\text { * Follo } \\
\dagger \text { Amin } \\
\ddagger \text { Value }\end{array}$ & $\begin{array}{l}\text { ified. } \\
\text { lydrolysis in } \\
\text { residues pr } \\
\text { sted to com }\end{array}$ & $\begin{array}{l}\text { ant boil } \\
\text { from } \\
\text { e for lo }\end{array}$ & $\begin{array}{l}\text { for } 20 \text { at } \\
\text { n gene cod } \\
\text { ring hydrol }\end{array}$ & gion. & \\
\hline
\end{tabular}

Following tryptic digestion of the resolubilized pellet obtained by treatment of pilin with trifluoroacetic acid, a number of peptide fragments were purified by high pressure liquid chromatography. With one exception these corresponded to peptides expected from trypsin digestion, each containing a $\mathrm{C}$-terminal lysine or arginine residue. The amino acid composition of the exceptional peptide (peptide 2, Table 1) corresponded to that of the predicted sequence from residues 67-72. The absence of lysine or arginine indicated that this peptide constituted the carboxy terminus of the amino-terminal pilin subunit. The sequence of this peptide was confirmed by gas phase sequence analysis. Amino acid analysis of a tryptic peptide isolated from the supernatant fraction showed that it corresponded to residues 73-97 of the predicted mature pilin sequence (peptide 3, Table 1). Together these peptide compositions and the sequence analysis demonstrate that the cleavage point occurs between residues 72 and 73 of the mature pilin sequence, resulting in predicted polypeptides of calculated $M_{\mathrm{r}}$ values of $7200(\mathrm{~N}$-terminal polypeptide) and 9200 (C-terminal polypeptide). The discrepancy between the latter value and that observed on SDS-PAGE (Fig. 4) is similar to that previously observed with the C-terminal polypeptide of pilin from Bn 265 and may reflect the unreliability of gel-derived $M_{\mathrm{r}}$ estimates for proteins of $M_{\mathrm{r}}$ less than $\sim 15000$ (Elleman et al., 1986b).

\section{DISCUSSION}

The nucleotide sequence determined for the pilin gene of Bn351 encodes a single polypeptide of $M_{\mathrm{r}} 17150$ which, after removal of the seven-amino-acid leader sequence and methylation of the new amino-terminal residue, would give a mature pilin of $M_{\mathrm{r}} 16392$. However, SDS-PAGE of pili isolated from Bn351 shows two distinct bands as a result of cleavage of the pilin subunit. 
The site of the peptide bond cleavage within the molecule is between ${ }_{72} \mathrm{Ala}$ and ${ }_{73} \mathrm{Ser}$ of mature pilin. This position is identical to the position of cleavage determined for pilin from Bn265, a representative of serogroup $\mathrm{Hl}$, in which cleavage occurs between ${ }_{72} \mathrm{Ala}$ and ${ }_{73} \mathrm{Ala}$. The agents responsible for the breakage of the peptide bond and amino-terminal blocking have not been determined for either strain. The cleavage is probably not a result of the isolation procedure since Bn 265 pili produced in Pseudomonas aeriginosa (Elleman \& Stewart, 1988) and isolated by the same procedure as used in this study, are composed of uncleaved pilin subunits. A probable explanation of the cleavage, given the production of a number of secreted proteases by $\boldsymbol{B}$. nodosus isolates (Kortt et al., 1986), is an extracellular protease acting on susceptible sites within the intact pilus.

Known pilin sequences from $B$. nodosus isolates clearly fall into two distinct sets, with members of a set possessing greater sequence similarity to each other than to any member of the other set. An obvious feature which distinguishes members of the two sets is the number and position of cysteine residues. The A-set pilins, comprising pilins from serogroups A, B, C, E, F, $\mathrm{G}$ and probably I, possess a single, centrally-located disulphide bridge, whereas $\mathrm{D}$-set pilins, from serogroups $\mathrm{D}$ and $\mathrm{H}$, have a carboxy-terminal-located disulphide bridge in addition to a more centrally located bridge. Aligned amino acid sequences of pilins from the two sets show greater than $59 \%$ sequence identity for members of the same set, but less than $39 \%$ identity for members of different sets. On the basis of sequence comparisons and the position and number of cysteine residues, pilin from strain 351 clearly is a member of the D-set.

Comparison of pilin polypeptides from the three B. nodosus strains 351,340 and 265 indicates that they are closely related, with $\mathrm{Bn} 351$ and $\mathrm{Br} 265$ sharing the closest relationship (Fig. 2). The amino-terminal regions of the three sequences are almost identical, suggesting that the important antigenic determinants are located in the carboxy-terminal regions of the molecules. The relative relationships displayed between $\mathrm{Bn} 351, \mathrm{Bn} 340$ and $\mathrm{Bn} 265$ as judged by comparison of both the amino acid sequences of pilins and the nucleotide sequences of the coding regions of the pilin genes is not reflected in comparisons of sequence flanking the coding regions. In particular, the pilins of $\mathrm{Bn} 351$ and $\mathrm{Bn} 265$ appear to be the most closely related, whereas in the regions flanking the pilin coding region, $\mathrm{Bn} 351$ and $\mathrm{Bn} 340$ exhibit the closer relationship. This disparity may indicate the occurrence of genetic rearrangements in ancestral strains, possibly through homologous recombination.

In Neiserria gonorrhoeae, antigenic variation of pilin has been linked to the existence of silent pilin loci with the expression of new antigenic forms facilitated by intrachromosomal recombination between these silent loci and the active expression locus (Koomey et al., 1987). However B. nodosus, like $P$. aeruginosa (Strom \& Lory, 1986), possesses only a single detectable pilin and therefore $B$. nodosus pilin must rely on a different mechanism to generate antigenic change. Antigenic diversity among $B$. nodosus pilins could result from point mutations, insertions and deletions within the pilin gene, although, as with $P$. aeruginosa (Johnson et al., 1986), the possibility of intrachromosomal recombination between regions of low sequence identity cannot be excluded.

Pilin of $\mathrm{Bn} 351$ (serogroup $\mathrm{H} 2$ ) has $80 \%$ sequence identity to pilin from $\mathrm{Bn} 265$ (serogroup $\mathrm{H} 1$ ), which is greater than the identity $(69 \%)$ of $\mathrm{Bn} 265$ to $\mathrm{Bn} 340$ (serogroup D). However, the level of sequence identity between pilins from $\mathrm{Bn} 265(\mathrm{H} 1)$ and $\mathrm{Bn} 351$ (H2) is considerably lower than has been found between pilins of strains from different subgroups within a serogroup. For example, comparison of pilin sequences from $\mathrm{Bn} 198$ (A1) and $\mathrm{Bn} 286$ (A2), strains representative of the two subgroups of serogroup A, indicates $95 \%$ identity (P. A. Hoyne, unpublished data), while comparison of four sequences from strains representing the four subgroups of serogroup B reveals similarly high levels of identity between any two sequences (T. C. Elleman, unpublished data). In addition, the level of identity between the predicted amino acid sequences of pilins from $\mathrm{Bn} 265(\mathrm{H} 1)$ and $\mathrm{Bn} 351(\mathrm{H} 2)$ is lower than that found between pilins of some strains belonging to different serogroups. For example, comparison of amino acid sequences of Bn216 (serogroup E) and Bn 1017 (serogroup F) indicates $81 \%$ identity. These observations suggest that $\mathrm{Bn} 351$ and $\mathrm{Bn} 265$ differ sufficiently from each other to preclude their assignment to the same serogroup. Recent serological studies support this conclusion and fail to classify Bn351 as a 
member of serogroup H (S. E. J. Thorley, personal communication). Using the alternative classification system of Day et al. (1986), Bn265 and Bn351 are classified as different serotypes; $\mathrm{Bn} 265$ is classified as serotype $\mathrm{H}$ whereas Bn351 is classified as serotype $\mathrm{O}$ (S. E. J. Thorley, personal communication). Furthermore, vaccination trials precipitated by our sequence observations have shown that pili from Bn351 fail to protect sheep from footrot when challenged with Bn265 (D. J. Stewart, unpublished data). To accommodate Bn351 into the scheme of Claxton et al. (1983) would require extension of the system by addition of a new serogroup having $\mathrm{Bn} 35 \mathrm{l}$ as its prototype strain.

The authors thank Mrs S. Letho for technical assistance and Mr P. Strike for gas-phase sequence analysis. We are indebted to Professor J. R. Egerton, Department of Veterinary Studies, University of Sydney for the gift of a freeze dried culture of B. nodosus VCS1057 and to Ms J. Vaughan of CSIRO Division of Animal Health for culturing the bacterium.

\section{REFERENCES}

Ausubel, F. M. (1984). Regulation of nitrogen fixation genes. Cell 37, 5-6

Anderson, B. J., Mattick, J. S., Cox, P. T., Kristo, C. L. \& Egerton, J. R. (1987). Western blot (immunoblot) analysis of the fimbrial antigens of Bacteroides nodosus. Journal of Bacteriology 169, 4018-4023.

Beveridge, W. I. B. (1941). Foot-rot in sheep: a transmissible disease due to infection with Fusiformis nodosus. Bulletin no. 140, Council for Scientific and Industrial Research, Melbourne.

Claxton, P. D. (1986). Serogrouping of Bacteroides nodosus isolates. In Footrot in Ruminants, pp. 131134. Edited by D. J. Stewart, J. E. Peterson, N. M. McKern \& D. L. Emery. Sydney: CSIRO Australia and Australian Wool Corporation.

Claxton, P. D., Ribeiro, L. A. \& Egerton, J. R. (1983). Classification of Bacteroides nodosus by agglutination tests. Australian Veterinary Journal 60, 331-334.

DalRymple, B. \& Mattick, J. S. (1987). An analysis of the organization and evolution of type 4 fimbrial (MePhe) subunit proteins. Journal of Molecular Evolution 25, 261-269.

DAy, S. E. J., Thorley, C. M. \& Beesley, J. E. (1986). Serotyping of Bacteroides nodosus: proposal for 9 further serotypes $(\mathbf{J}-\mathbf{R})$ and a study of the antigenic complexity of $B$. nodosus pili. In Footrot in Ruminants, pp. 147-159. Edited by D. J. Stewart, J. E. Peterson, N. M. McKern \& D. L. Emery. Sydney: CSIRO Australian and Australian Wool Corporation.

Egerton, J. R. \& Burrell, D. H. (1970). Prophylactic and therapeutic vaccination against ovine foot-rot. Australian Veterinary Journal 46, 517-522.

EgERTon, J. R. \& Roberts, D. S. (1971). Vaccination against ovine foot-rot. Journal of Comparative Pathology 81, 179-185.

Elleman, T. C. (1988). Pilins of Bacteroides nodosus: molecular basis of serotypic variation and relationships to other bacterial pilins. Microbiological Reviews 52, 233 $\cdots 247$

Elleman, T. C. \& Hoyne, P. A. (1984). Nucleotide sequence of the gene encoding pilin of Bacteroides nodosus, the causal organism of ovine footrot. Journal of Bacteriology 160, 1184-1187.

Elleman, T. C. \& STEwart, D. J. (1988). Efficacy against footrot of a Bacteroides nodosus 265 (serogroup $\mathrm{H}$ ) pilus vaccine expressed in Pseudomonas aeruginosa. Infection and Immunity 56, 595-600.

Elleman, T. C. \& VON AhlefeldT, D. A. (1987). Nucleotide sequence of the pilin gene from Bacteroides nodosus strain 238 (serogroup G). Nucleic Acids Research 15, 7189.

Elleman, T. C., Hoyne, P. A., Emery, D. L., STEWART, D. J. \& ClARK, B. L. (1984). Isolation of the gene encoding pilin of Bacteroides nodosus (strain 198), the causal organism of ovine footrot. FEBS Letters 173, 103-107.

Elleman, T. C., Hoyne, P. A., McKern, N. M., EMery, D. L., Stewart, D. J. \& Clark, B. L. (1986a). Isolation and characterisation of the gene encoding pilin of Bacteroides nodosus (strain 198) and its expression in Escherichia coli. In Footrot in Ruminants, pp. 257-261. Edited by D. J. Stewart, J. E. Peterson, N. M. McKern \& D. L. Emery. Sydney: CSIRO Australian and Australian Wool Corporation.

Elleman, T. C., Hoyne, P. A., MCKern, N. M. \& STEWART, D. J. (1986 b). Nucleotide sequence of the gene encoding the two-subunit pilin of Bacteroides nodosus 265. Journal of Bacteriology 167, 243250.

Elleman, T. C., Hoyne, P. A., Stewart, D. J. McKern, N. M. \& Peterson, J. E. (1986c). Expression of pili from Bacteroides nodosus in Pseudomonas aeruginosa. Journal of Bacteriology 168, 574-580.

Every, D. \& Skerman, T. M. (1982). Protection of sheep against experimental footrot by vaccination with pili purified from Bacteroides nodosus. New Zealand Veterinary Journal 30, 156-158.

Finney, K. G., Elleman, T. C. \& Stewart, D. J. (1988). Nucleotide sequence of the pilin gene of Bacteroides nodosus 340 (serogroup D) and implications for the relatedness of serogroups. Journal of General Microbiology 134, 575-584.

Johnson, K., Parker, M. L. \& Lory, S. (1986). Nucleotide sequence and transcriptional initiation site of two Pseudomonas aeruginosa pilin genes. Journal of Biological Chemistry 261, 15703-15708.

Koomey, M., Gotschlich, E. C., Robbins, K., BergSTROM, S. \& Swanson, J. (1987). Effects of recA mutations on pilus antigenic variation and phase 
transitions in Neisseria gonorrhoeae. Genetics 117 , 391-398.

Kortt, A. A., Caldwell, J. B., Burns, J. E., Guthrie, R. E. \& STEwart, D. J. (1986). Characterisation and substrate specificity of the extracellular proteases of Bacteroides nodosus from virulent and benign ovine isolates. In Footrot in Ruminants, pp. 237-243. Edited by D. J. Stewart, J. E. Peterson, N. M. McKern \& D. L. Emery. Sydney: CSIRO Australia and Australian Wool Corporation.

LAEMMLI, U. K. (1970). Cleavage of structural proteins during assembly of the head of bacteriophage T4 Nature, London 227, 680-685.

Maniatis, T., Fritsch, E. F. \& Sambrook, J. (1982). Molecular Cloning: a Laboratory Manual, pp. 326328. Cold Spring Harbor NY: Cold Spring Harbor Laboratory.

Messing, J. (1983). New Ml3 vectors for cloning. Methods in Enzymology 101, 20-78.

MCKern, N. M., O'Donnell, I. J., Inglis, A. S., Stewart, D. J. \& Clark, B. L. (1983). Amino acid sequence of pilin from Bacteroides nodosus (strain 198), the causative organism of ovine footrot. FEBS Letters 164, 149 153.

MCKern, N. M., O'Donnell, I. J., Stewart, D. J. \& Clark, B. L. (1985). Primary structure of pilin protein from Bacteroides nodosus strain 216: comparison with the corresponding protein from strain 198. Journal of General Microbiology 131, 1-6.

McKern, N. M., Stewart, D. J. \& Strike, P. M. (1988). Amino acid sequences of pilins from serologically distinct strains of Bacteroides nodosus. Journal of Protein Chemistry 7, 157-164.

Needleman, S. B. \& Wunsch, C. D. (1970). A general method applicable to the search for similarities in the amino acid sequence of two proteins. Journal of Molecular Biology 48, 443-453.
Platt, T. (1986). Transcription termination and the regulation of gene expression. Annual Review of Biochemistry 55, 339-372.

Radloff, R., Bauer, W. \& Vinograd, J. (1967). A dye-bouyant-density method for the detection and isolation of closed circular duplex DNA : the closed circular DNA in HeLa cells. Proceedings of the National Academy of Sciences of the United States of America 57, 1514-1521.

Sanger, F., Nicklen, S. \& Coulson, A. R. (1977). DNA sequencing with chain-terminating inhibitors. Proceedings of the National Academy of Sciences of the United States of America 74, 5463-5467.

Smith, G. E. \& Summers, M. D. (1980). The bidirectional transfer of DNA and RNA to nitrocellulose or diazobenzyloxymethyl-paper. Analytical Biochemistry 109, 123-129.

STEWART, D. J. (1978a). The role of various antigenic fractions of Bacteroides nodosus in eliciting protection against foot-rot in vaccinated sheep. Research in Veterinary Science 24, 14-19.

Stewart, D. J. $(1978 b)$. Studies on the antigenic structure of Bacteroides nodosus. Research in Veterinary Science 24, 293-299.

Stewart, D. J., Clark, B. L., Peterson, J. E., Griffiths, D. A., SMith, E. F. \& O'DONNELl, I. J. (1983). Effect of pilus dose and type of Freund's adjuvant on the antibody and protective responses of vaccinated sheep to Bacteroides nodosus. Research in Veterinary Science 35, 130-137.

Strom, M. S. \& LORY, S. (1986). Cloning and expression of the pilin gene of Pseudomonas aeruginosa PAK in Escherichia coli. Journal of Bacteriology 165, 367-372.

Stormo, G. D., Schneider, T. D. \& Gold, L. M. (1982). Characterization of translational initiation sites in E. coli. Nucleic Acids Research 10, 2971-2996. 